\title{
Systemic trauma in the Black community: My perspective as an Asian American
}

\section{Christopher Villongco, MD}

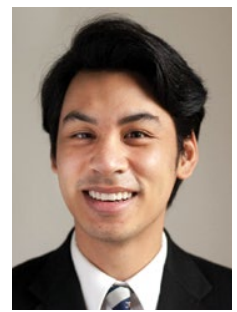

Dr. Villongco is a PGY-3 Psychiatry Resident, Department of Psychiatry \& Behavioral Sciences, Morehouse School of Medicine, Atlanta, Georgia.

\section{Disclosure}

The author reports no financial relationships with any companies whose products are mentioned in this article, or with manufacturers of competing products.

\section{Acknowledgment}

The author thanks Shawn Garrison, $\mathrm{PhD}$, Assistant Professor of Psychiatry \& Behavioral Science, Morehouse School of Medicine, Atlanta, Georgia, for her collaboration on this article.

doi: 10.12788/cp.0126

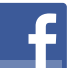

Discuss this article at www.facebook.com/ MDedgePsychiatry
$\mathrm{B}$ eing a physician gives me great privilege. However, this privilege did not start the moment I donned the white coat, but when I was born Asian American, to parents who hold advanced education degrees. It grew when our family moved to a White neighborhood and I was accepted into an elite college. For medical school and residency, I chose an academic program embedded in an urban setting that serves underprivileged minority communities. I entered psychiatry to facilitate healing. Yet as I read the headlines about people of color who had died at the hands of law enforcement, I found myself feeling overwhelmingly hopeless and numb.

In these individuals, I saw people who looked and lived just like the patients I chose to serve. But during this time, I did not see myself as the healer, but part of the system that brought pain and distress. As an Asian American, I identified with Tou Thao-the Asian American police officer involved in George Floyd's death. In the medical community with which I identified, I found that ever-rising cases of COVID-19 were disproportionately affecting lower-income minority communities. In a polarizing world, I felt my Asian American identity prevented me from experiencing the pain and suffering Black communities faced. This was not my fight, and if it was, I was more immersed in the side that brought trauma to my patients. From a purely rational perspective, I had no right to feel sad. Intellectually, I felt unqualified to share in their pain, yet here I was, crying in my room.

\section{An evolving transformation}

As much as I wanted to take a break, training did not stop. A transformation occurred from an emerging awareness of the unique environment within which I was training and the intersection of who I knew myself to be. Serving in an urban program, I was given the opportunity for candid conversations with health professionals of color. I was humbled when Black colleagues proactively reached out to educate me about the historical context of these events and help me process them. I asked hard questions of my fellow residents who were Black, and listened to their answers and personal stories, which was difficult.

With my patients, I began to listen more intently and think about the systemic issues I had previously written off. One patient missed their appointment because public transportation was closed due to COVID-19. Another patient who was homeless was helped immensely by assistance with housing when he could no longer sleep at his place of residence. Really listening to him revealed that his street had become a common route for protests. With my therapy patient who experienced panic attacks listening to the news, I simply sat and grieved with them.

LET YOUR VOICE BE HEARD

CURRENT PsyChIATRY invites psychiatry residents to share their views on professional or clinical topics for publication in Residents' Voices. E-mail jbauer@mdedge.com for author guidelines. 
I chose these interactions not because I was uniquely qualified, intelligent, or had any ability to change the trajectory of our country, but because they grew from me simply working in the context I chose and seeking the relationships I naturally sought.

\section{How I define myself}

As doctors, we accept the burden of caring for society's ailments with the ultimate hope of celebrating triumph over the adversity of psychiatric illness. However, superseding our profession is the social system in which we live. I am part of a system that has historically caused trauma to some while benefitting others. Thus, between the calling of my practice and the country I practice in, I found a divergence. Once I accepted the truth of this system and the very personal way it affects me, my colleagues, and patients I serve, I was able to internally reconcile and rediscover hope. While I cannot change my experiences, advantages, or privilege, these facts do not change the reality that I am a citizen of the globe and human first. This realization is the silver lining of these perilous times; training among people of color who graciously included me in their experiences, and my willingness to listen and self-reflect. Inow choose to define myself by what makes me similar to my patients instead of what isolates me from them. The tangible results of this deliberate step toward authenticity are renewed inspiration and joy.

For those of you who may have found yourself with no "ethnic home team" (or a desire for a new one), I leave you with this simple charge: Let your emotional reactions guide you to truth, and challenge yourself to process them with someone who doesn't look like you. Leave your title at the door and embrace humility. You might be pleasantly surprised at the human you find when you look in the mirror.

\section{Clinical Point \\ I now choose to define myself by what makes me similar to my patients instead of what isolates me from them}

